\title{
Institutional Collaborations in Ireland: Leveraging an Increased International Presence
}

\author{
Pamela L. Eddy \\ College of William and Mary, pamela.eddy@wm.edu
}

Follow this and additional works at: https://scholarworks.wm.edu/educationbookchapters

Part of the International and Comparative Education Commons

\section{Recommended Citation}

Eddy, Pamela L., "Institutional Collaborations in Ireland: Leveraging an Increased International Presence" (2010). School of Education Book Chapters. 34.

https://scholarworks.wm.edu/educationbookchapters/34

This Book Chapter is brought to you for free and open access by the School of Education at W\&M ScholarWorks. It has been accepted for inclusion in School of Education Book Chapters by an authorized administrator of W\&M ScholarWorks. For more information, please contact scholarworks@wm.edu. 
Five case examples highlight how Ireland is using collabora-

tions to meet national goals.

\title{
Institutional Collaborations in Ireland: Leveraging an Increased International Presence
}

\author{
Pamela L. Eddy
}

This chapter highlights how shifts in policy within Ireland toward increased global rankings and quality of educational programs and a heightened interest in research have been operationalized on the ground. The Higher Education Authority initiated a Programme for Research in Third-Level Institutions (PRTLI) to provide seed money for research innovation. The research reported here provides an overview of the funding program and showcases five of the funded programs, highlighting how these research collaborations have aided in reaching the goals set in Ireland. Lessons learned include the influential role of the external context, including the Bologna Process and involvement in the European Union (EU), and the unintended impact of pitting institutions against one another. Role transitions from competitor to collaborator were not instantaneous or always long lasting. The role of the champion of the partnership was heightened given the size of the country. Finally, structural features of the funding process worked against sustainability for the partners. Lessons from this research are apparent for partners, faculty members, and policy makers.

\section{Case Studies of Collaboration}

The Higher Education Authority (HEA) initiated its Programme for Research in Third Level Institutions (PRTLI) in 1998; to date, four cycles of funding have been awarded, with a fifth cycle of funding proposals started 
in 2009. Delays in the awarding of Cycle 5 funds have occurred due to the budget difficulties facing Ireland. As of mid-2010, award winners had still not been selected. In the first four cycles, a total of $€ 865,273,117$ was distributed among 83 funded projects. The HEA emphasized different areas of foci for each of the grant cycles, with increasing emphasis on collaboration and partnerships occurring over time. Programs received one-time funding, with an expectation that they would be self-sustaining when the grant funding ended. Several projects, however, expanded their orientation, scope, partners, and area of coverage in the country and were successful in receiving funding during multiple cycles.

The landscape of postsecondary education in Ireland includes 21 main publicly funded tertiary institutions, seven of them universities and 14 of them institutes of technology (IoT) (Organisation for Economic Co-operation and Development, 2006). Since 2001, the Dublin Institute of Technology (DIT) obtained full degree-granting rights for first masters and doctoral degrees. DIT is the largest of the institutes and differs from other institutes given its age, size, and location, which serves a broad range of educational and technical needs. Some of the universities and IoTs were involved in multiple projects, whereas others were not involved at all. Some universities were well positioned and poised to participate in applications for funding given their established inclusion of a research mission, albeit at a lower level than elsewhere in Europe, whereas other institutions were new to the researching enterprise.

How were the partnerships enacted within the funded research projects? How do partnerships impact changes in research in Ireland? What is the impact on faculty work? What organizational changes result from the partnerships? These are the research questions underpinning this study. Case study methodology was employed to closely examine the interactions among partners and to provide more depth of analysis. The investigation of multiple sites within Ireland allowed for cross-case comparisons. Data collection occurred via case site visits to allow for direct observation of the organizations and participants. Interviews were conducted with key partnership personnel and leaders.

Case sites were purposely selected among the funded projects. First, a range of funded areas was sought to determine the influence of disciplinary orientation on the partnership process. Second, cases were selected that involved a breadth of partners from as few as two to as many as eight. Cases were also selected based on the different types of partnering institutions involved since some included non-third-level organizations. Finally, cases were selected to investigate those most recently funded for the first time in Cycle 4 to those who had received funding over multiple cycles through shifting and expanded projects. The case sites included e-INIS/Cosmogrid (Irish National Infrastructure), the Environmental Change Institute (ECI), the Graduate School of Creative Arts and Media (GradCAM), the Humanities Serving Irish Society (HSIS), and Molecular Medicine Ireland (MMI). 
e-INIS/Cosmogrid. Cosmogrid and e-INIS (Irish National Infrastructure) are closely linked projects, with e-INIS (e-INIS-Irish National Infrastructure, n.d.) evolving from the project established by Cosmogrid. Cosmogrid received $€ 11.8$ million under PRTLI Cycle 3 to establish a program for research on grid-enabled computational physics of natural phenomena. The lead institution was Dublin Institute for Advanced Studies and partners included Dublin City University, National University of Ireland (NUI) Galway, University College Dublin (UCD), HEAnet, Met Éireann, Armagh Observatory, and Grid Ireland. The initial project supported building a national grid system within the country that took advantage of pooling excess capacity within the technology infrastructure system to deliver uniform and reliable service. The grid provides the technology platform upon which academics and users can take advantage of the power of the computer infrastructure to conduct research. This project brought together users and providers of the infrastructure to take advantage of a pooling of computational resources. In 2006, Cosmogrid published A White Paper on Irish e-Infrastructure, which contributed to the argument for funding for e-INIS in Cycle 4. A spin-off of Cosmogrid is ICHEC-Irish Centre for High-End Computing. ICHEC provides space with high-end computing available to researchers and graduate students.

In PRTLI Cycle 4, e-INIS received $€ 12.5$ million and included the following partners: Dublin Institute of Advanced Studies, NUI Galway, NUI Maynooth, Trinity College Dublin, and UCD. The goal of e-INIS is to create a federation of electronic infrastructure providers in Ireland, in conjunction with the country's universities. The sharing of resources provides a platform for research that connects all the third-level programs within Ireland and provides a national data service to help coordinate activities. One project utilizing the e-infrastructure is the Digital Humanities Observatory (DHO), a funded project of HSIS. This Web resource serves as an e-resource for the humanities. A Cycle 5 proposal is in the works to help extend the computing infrastructure. The establishment of a group with a common focus for e-infrastructure in Ireland was modeled on best practices in Europe.

Environmental Change Institute. The Environmental Change Institute (ECI) at the NUI, Galway was founded in September 2000 through a commitment of $€ 9.6$ million in funding from both private sources and Ireland's Higher Education Authority under Cycle 2 of PRTLI. The ECI is a research center within the Institute for Environmental Studies, a cooperative initiative between the three western Irish seaboard Universities (NUI Galway, University College Cork, and University of Limerick), which together form the Atlantic University Alliance (ECI-Environmental Change Institute, n.d.). Since this initial funding in Cycle 2, NUI Galway has received funding for $€ 1.0$ million for a new research program under Cycle 3 as well. The Institute also received funding under Cycle 4 for a total of $€ 11.6$ million and worked with the following partners: Cork Institute of Technology, NUI 
Maynooth, Trinity College Dublin, University College Cork, and University College Limerick.

The administrators of the institute took a focused approach in the preparation of the Cycle 5 bid. Their proposal centered on climate change and addresses three specific thematic areas. Crossing these main areas were two key capacity building areas-Environmental Research Capacity Development and Informatics, Quantification, and Predictive Capacity Development. As institutional representatives came to the preliminary discussions with varying ideas, the focus was always placed back on the central driving themes. If these themes did not fit with the institutional partner's ideas, they were not included. Constant focusing on the central themes helped drive the discussion, though there were moments of heated dissension in arriving at the final proposal. The alignment of the vision of the two central institutions (NUI Galway and UCC) helped drive the overall process.

Graduate School of Creative Arts and Media. The Graduate School of Creative Arts and Media (GradCAM; GradCam-Graduate School of Creative Arts and Media, n.d.) received $€ 2.1$ million in funding through PRTLI Cycle 4 to create a structured Ph.D. program in the area of creative arts and media. There are two named partners for this collaboration: Dublin Institute of Technology (DIT) and the National College of Art and Design (NCAD). Two additional collaborators include the Institute of Art, Design and Technology, Dún Laoghaire (IADT) and the University of Ulster (UU). After funding was announced for GradCAM in fall 2007, a process began to recruit the first doctoral fellows. Eight students began studies in February 2008 and a year later this cohort grew to 15 funded students and four selffunded students. NCAD provided the office location for the collaboration as an in-kind donation, with space available for training seminars, student offices, and meeting space.

Contributing to the success of the partnership was a long history of working together in the area of creative arts. A conference in early 2000 brought the partners together and conversations arose from these meetings regarding advanced degree options, with all institutions realizing that the demand was not great enough for them to go it alone. One of the first initiatives of GradCAM was to create a logo for the new initiative. This symbolized the creation of the partnership and is used on all printed material. Slowly, the concept of GradCAM is growing as a recognized entity in the country. The proposal put forth by GradCAM for Cycle 5 builds on the success of the current funding, namely specific structured Ph.D. programs. In the current proposal, new partners were added on, including an official place for IADT and the addition of UCD to help provide a national platform for the projects. As with other projects seeking funding under Cycle 5, tensions were evident as individual institutions jockeyed for high institutional priority on their own campuses and often were pulled into competition on other bids.

Humanities Serving Irish Society. Humanities Serving Irish Society (HSIS) is a consortium of eight universities (Dublin City University, NUI 
Galway, NUI Maynooth, National College of Art and Design, Royal Irish Academy, Trinity College Dublin, University College Cork, and University College Dublin) that was funded under PRTLI Cycle 4 for $€ 28.9$ million. Of note, each of the participating universities rated HSIS as a top priority in their letters of support during the funding evaluation. Furthermore, previous PRTLI funding cycles had not supported humanities-based research partnerships, thus the HEA review panel was inclined to support HSIS. The Royal Irish Academy (RIA) serves as a neutral convener for the various humanities research projects and the HSIS Web site showcases the range of research underway. The RIA published a monograph titled Advancing Humanities and Social Science Research in Ireland. The paper served as the foundation argument for the creation of HSIS under Cycle 4. The HSIS acts as an umbrella group with research clusters among institutions under this structure. A precursor to HSIS was the creation of the Moore Institute at NUI Galway.

The main collaboration effort of HSIS is the Digital Humanities Observatory (DHO). This project involves the creation of a Web-based humanities resource. This project entails the storage and preservation of digital sources in the humanities, with access available to a wide range of users. DHO is supported by the e-infrastructure developed by the Cosmogrid program outlined above.

"The DHO will work to ensure a set of common standards based on best international practice to enable the fullest exploitation of existing national research collections and data repositories. In doing so, the DHO will be filling a critical gap in Ireland's humanities research infrastructure, as identified by a wide range of policy documents and reviews including the Academy's report: Advancing Humanities and Social Science Research in Ireland. The DHO will also incorporate a strong teaching and learning aspect by contributing seminars to a HSIS bi-semestrial postgraduate seminar series as well as organizing its own annual standards seminars and technical workshops" (HSIS-Humanities Serving Irish Society, n.d.). A PRTLI Cycle 5 proposal was put forth with NUI Maynooth as the lead institution. The proposal is for a structured Ph.D. program in the humanities with a focus on digital process. Like other partnerships in Cycle 5, HSIS was split by the tensions among member institutions. In the end, University College Dublin pulled out of the collaboration and put forth its own proposal.

Molecular Medicine of Ireland. Molecular Medicine of Ireland (MMI) is a "not for profit company established [in 2007] by the National University of Ireland Galway, the Royal College of Surgeons in Ireland, Trinity College Dublin, University College Cork, and University College Dublin to coordinate their biomedical research and education activities" (MMI-Molecular Medicine of Ireland, n.d.). MMI received funding to aid in its establishment under PRTLI Cycle 4. In addition to the founding of the national organization, the funding under Cycle 4 supported a Clinician Scientist Fellowship Programme involving all partnering universities; $€ 11.2$ million was awarded. 
MMI is built upon the foundation established by Dublin Molecular Medicine Centre (DMMC). DMMC was established in 2002 as a partnership among Trinity College Dublin, University College Dublin, the Royal College of Surgeons, and their associated hospitals. This collaboration received $€ 44.8$ million under PRTLI Cycle 3 for the creation of the Programme for Human Genomics. Tracing further back, the genesis of DMMC is rooted in funding under PRTLI Cycle 2 when a total of $€ 26$ million was awarded to UCD and TCD to establish a partnership to bring together key researchers in the country to pool resources and expertise for the study of molecular medicine.

The evolution of the study of molecular medicine from a regional focus in Dublin to the current national collaboration highlights the push for collaborations in Ireland. The critical mass of expertise among the partners provides leverage to accomplish more than any single institution could do on its own. A tension exists, however, in the current partnership since the Royal College of Surgeons in Ireland opted not to participate in the PRTLI Cycle 5 proposal put forth by MMI. Instead, the RCSI put in a competing bid for funding with other partnering institutions. A clear dilemma of dual loyalties to the MMI collaborative and to institutional priorities was evident. NUI Galway took the lead on the Cycle 5 proposal for MMI. What remains unknown is how the opting out of the Cycle 5 funding bid by RCSI will impact the overall objectives of MMI or how this larger collaboration will adjust. The RCSI is still involved in the Clinician Scientist Programme under Cycle 4 and this project continues until 2010.

\section{Findings}

The national goals for higher education in Ireland are linked to Ireland's National Development Plan (NDP), 2007-2013-Transforming Ireland (Irish Government, 2009). Education figures prominently into the strategic plan and the Higher Education Authority (HEA) has incorporated the national goals and objectives into their own plans. The focus for the tertiary education system centers on increasing access to higher education, increasing Ph.D. students within the country, and increasing institutional prominence within the EU. The NDP underscores the need for collaborations to achieve the goals outlined, thus tertiary institutions in Ireland are motivated to partner in attempts to meet national goals. Supporting this platform for collaboration is the HEA funding in PRTLI, which increased its emphasis on the role of partnering to obtain grant monies.

The research conducted on the case sites identified above found four key findings. First, the type of motivation for partnering contributed to the alignment of values and mission among partners. Those with similar value structures and mission beliefs were able to weather storms of conflict because there was a basis for the collaboration beyond funding. For some of the cases, it was a matter of convenient alliances, whereas for others there 
was shared interest in obtaining a common outcome from the collaboration. Second, the role of an internal champion for the partnership made a difference. The amount of social capital possessed by the champion contributed to how quickly the partnership formed and how well it operated. Third, the partnerships had impacts on individual institutional operations and ultimately on faculty work. Policies were created to deal with the newly formed collaborative entities, some of which impacted individual campus policies as well. For the most part, the work done within the partnership was added to faculty obligations, most often without any additional compensation or acknowledgment from within the institution. Finally, the external context influenced outcomes. Ireland is nested within several larger systems that contribute to internal policy and outcomes. For instance, as a member of the EU, practices in this larger entity influence the norms within the country, particularly in the sciences. Participation in the EU also increases the potential partners available to faculty and universities that may supersede partnerships possible within the country.

Motivation and Value Alignment. Various motivations contribute to how partnerships were formed, how they operated, and how they were held together. Clearly, the availability of extra funding was a motivator for all the partnerships. The infusion of funding to support collaborative research and to create doctoral programs was a new phenomenon in the country. Each college had to rate the proposals put forward to the HEA, basing their priorities on the internal needs and missions of the individual institutions and the alignment with the request for funding programs by the HEA.

In two of the cases outlined above, groups had published white papers that reviewed the state of programming and research needs within the discipline. This preparatory work laid a firm foundation for arguments they put forth in their funding proposals and added a sense of legitimacy to the partnership. HSIS and Cosmogrid both built their proposals on the findings of the needs assessments the partners conducted for the white papers to show the rationale for the projects. The white paper served to bring the group together and began to create a sense of a shared understanding of goals for the collaborators.

The size of the country meant that the faculty members working on areas of common research were known to one another and that the faculty may have had previous working relationships through funding received within the EU or through one of the EU science foundations. Likewise, partners may have worked together in hosting a conference or previous smaller collaborations. The social network in the country made it possible to readily identify potential partners, but the shift from competitors to collaborators was not always smooth. The pull of loyalty to one's home institution and supporting the vision and goals of the college often ran counter to shared partnership projects. Value alignment often was high for those partnerships built in the disciplinary margins, such as the creative arts and in the humanities because alternative funding sources were limited. Areas in 
the sciences, on the other hand, had more options because there was funding through the science foundations and within the EU and the ability to partner with others outside the country. Also, faculty in the sciences had longer experience with grant-funding and the process of applying for funding.

Role of the Champion. The champion of the collaborative effort served as the initiator for the group, bringing together partners from around the country. This person also set the tone for the type of interactions that occurred among the partners, often negotiating conflict and serving as a final arbitrator in decision-making. Some institutions had reputations of working well together, whereas others were viewed as rogue partners merely following the money and having less altruistic reasons for participating.

The champions within the partnerships often had large levels of social capital accrued (Coleman, 1988). Social capital refers to the ability of individuals to leverage influence in relationships based on the strength and closeness of these relationships, the amount of trust established between players, and the intensity of these relationships relative to their importance to each other, the institution, and the partnership. Ireland is a small country, thus personal relationships with others in similar fields were common and often of long duration. Strong champions were able to use their influence to bring players together, but also were able to keep the peace when conflict arose. It was easy to be a champion when money was readily available, but less so when it was not. Those with higher levels of social capital navigated the lean times better.

Contributing to the relationship building was the labor market patterns within the country-faculty members and administrators exhibit less mobility than counterparts located in the United States. Generally, when a faculty member started their career in one institution, they stayed at this institution. This pattern often influenced loyalty to the institution over partners when disagreements emerged.

Impact on Organizations and Faculty Work. The partnerships created new entities and infrastructures; as a result, policies emerged as the collaboration developed. A project manager was identified for each of the funded projects and each manager often received either part or all of his or her salary from the funding or from in-kind support by one of the institutions. Funding also supported administrative staff for the newly formed partnership. Generally, a board was created to provide support for the project manager and consisted of representatives of each of the colleges or organizations involved. The individual members held allegiance to the partnership, but also to their home institution. As project polices were created, each institution had to react to ensure a meshing of the overarching policy with internal procedures.

Faculty members were involved in a number of different capacities. For instance, faculty members were assigned as supervisors within newly created Ph.D. programs. This supervision and leading of topic workshops or classes typically came on top of the faculty members' institutional assignment. It was 
unclear how this faculty work was valued within the tenure and promotion cycle.

External Context Influences Outcomes. Prior to the availability of funding within Ireland, the majority of grant monies came from awards within the EU. The awards were most often through EU-sponsored programs or through specific science foundation grants. Participants noted that one of the benefits of the HEA funding was that it did not have onerous reporting requirements. It was often unclear to the partners, however, how the reports they filed were used by the HEA. Partners were quick to state that if the difficulty of reporting increased, the benefit of seeking funds would decrease and that EU funding would be sought instead.

Not only did the partners collaborate with others within Ireland, they also worked with researchers and scholars throughout the EU. The structure of these outside collaborations influenced perceptions of how Ireland should be working. One partner who was familiar with the processes in the United Kingdom (UK) noted his perception of differences among collaborations in Ireland relative to the UK. He related that when funding shrank in the UK, there was a tighter bonding of the partners to one another and a focus on the partnership, whereas in Ireland, when funding decreased, partners were viewed as competitors and the tendency was for individual institutions to seek opportunities that benefited the individual college rather than the partnership.

\section{Lessons Learned}

Partnerships among higher education institutions in Ireland, and the success of these collaborations, were dependent on the voice of the champion. The amount of clout and influence that the champion possessed mattered in terms of who was at the table for conversations, the resources available, and the longevity of the group project. Champions with high levels of respect in the field and good relationship-based skills were the most successful. When the champion led the group to create common goals and a shared vision, the partnership was stronger. For example, INIS built on the success of Cosmogrid and sought to develop the technical infrastructure within the country. This focused goal helped shepherd the group through multiple funding opportunities both by the HEA and within the EU. The partnership focus did shift from its initial work with faculty working on the grid to more focus on the process of the infrastructure, but the strong overarching goals reinforced by the champion helped to weather these shifts.

Areas of struggle were evident in proposal creation for PRTLI Cycle 5. During the preparation of proposals, several partnerships were strained by competing demands of individual partners that were tied to shifts in institutional mission or to the belief that the college could do a better job of going it alone or by initiating a competing partnership proposal. How these tensions were handled dictated the outcomes for the existing partnership. 
The ECI was quite clear on its priorities and created a conceptual map to illustrate this work. When conversations veered from these common goals, potential and continuing partners were reminded of the ultimate outcome and told that their contributions needed to align with this shared view. Partners with other goals were not included in the proposal. Previous work with partners created a history of knowing who could work well in the group, who could follow through on deadlines and promises, and who could be productive collaborators.

Previous interactions among the partners served as a foundation for current partnerships, underscoring that history together matters. As outlined in the cases above, white papers and position briefs often served as the foundation for funded programs. The time invested in creating the white papers also afforded partners an opportunity to get to know one another and to build trust. The small size of the country enables a fertile ground to create relationships, but the downside is that memories of bad partnerships are long-standing and difficult to overcome. Of interest, during the timing of Cycle 5 calls for proposals, Trinity College Dublin and University College Dublin announced the creation of an innovation corridor. This unique arrangement was perceived as a sidebar deal that might undercut ongoing partnership relationships and threaten new proposals.

The current period of financial exigency means that pressure is mounting for partners to obtain funding. Now, the role of the champion becomes more critical, as do past successes of partnership outcomes. The tendencies in the partnerships were attempts to predict outcomes and to calculate the probability of success by partnering with one institution over another. This type of risk assessment meant that some partners were focused on obtaining the best deal versus on the project vision per se. The gains for some partners were solidified and commitment reinforced because resources were tight.

By far, the biggest conclusion of this research was the success of the HEA in increasing research efforts and collaboration among tertiary sites in a scant ten years of funding (Higher Education Authority, 2008). The HEA leveraged change through its requirements for funding, namely the requirement to collaborate with other institutions of higher education so as not to duplicate services. Knowing the influence of policy and funding on obtaining change can establish intentionality in how RFPs are used to influence policy.

The demise of the Celtic Tiger, the term used to describe the rapid expansion of the Irish economy between 1995 and 2007, leaves much unknown about the future. The decline of resources created uncertainty among partners and within the country. Can the larger goals of increasing reputation and prestige of Ireland's colleges be sustained in the current economic climate? The research reported here helps to emphasize components to successful partnerships, namely having a strong champion, shared goals, and 
interaction among partners to build trust. The HEA-funded partnerships reviewed in this research showcase how the projects have helped to increase research within the country through collaboration and also to increase the number of advanced trained Ph.D. students who will be able to carry on research in the future as well. Faculty worked within the partnerships to help support both research endeavors and supervision for Ph.D. students. What remains unknown is how this level of involvement will be sustained given the lack of a corresponding reward structure for this faculty work.

Changes to institutional policies will help codify how faculty are rewarded, as well as provide evidence that the partnerships are important to the individual colleges and have more chance for sustainability. Training team members on ways to address conflict and how to manage group dynamics would help in sustainability as well. In the final assessment, Ireland's partnerships among colleges leveraged advancement in achieving the NDP goals of increased international presence and the creation of a stronger infrastructure for higher education in the country.

\section{References}

Coleman, J. S. "Social Capital in the Creation of Human Capital." The American Journal of Sociology, 1988, 94, S95-S120.

ECI-Environmental Change Institute. n.d. Official Web site. Retrieved June 15, 2009, from http://www.nuigalway.ie/eci/

e-INIS-The Irish National Infrastructure. n.d. Official Web site. Retrieved June 15, 2009, from http://www.e-inis.ie/

GradCam-Graduate School of Creative Arts and Media. n.d. Official Web site. Retrieved June 15, 2009, from http://www.gradcam.ie/contact.php

Higher Education Authority. Transformations: How Research Is Changing Ireland. Dublin: Irish National Infrastructure, 2008.

HSIS-Humanities Serving Irish Society. n.d. Official Web site. Retrieved June 15, 2009, from http://www.hsis.ie/default.asp?DocID=330\&RevID $=\& T$ Tpl=1Template3.asp

Irish Government. National Development Plan 2007-2013: Transforming Ireland. Dublin: Government Publications, 2009.

MMI-Molecular Medicine of Ireland. n.d. Official Web site. Retrieved June 15, 2009, from http://www.molecularmedicineireland.ie/home

Organisation for Economic Co-operation and Development (OECD). Higher Education in Ireland: Reviews of National Policies for Education. Paris: OECD Publishing, 2006.

PAMELA L. EDDY is associate professor of Educational Policy, Planning, and Leadership at the College of William and Mary. 